\title{
Power Frequency Oscillation Suppression Using Two-Stage Optimized Fuzzy Logic Controller for Multigeneration System
}

\author{
Y. K. Bhateshvar and H. D. Mathur \\ EEE Department, BITS, Pilani Campus, Pilani 333031, India \\ Correspondence should be addressed to Y. K. Bhateshvar; yogeshbhateshvar@gmail.com
}

Received 8 November 2015; Revised 3 March 2016; Accepted 16 March 2016

Academic Editor: Bosukonda M. Mohan

Copyright ( 2016 Y. K. Bhateshvar and H. D. Mathur. This is an open access article distributed under the Creative Commons Attribution License, which permits unrestricted use, distribution, and reproduction in any medium, provided the original work is properly cited.

\begin{abstract}
This paper attempts to develop a linearized model of automatic generation control (AGC) for an interconnected two-area reheat type thermal power system in deregulated environment. A comparison between genetic algorithm optimized PID controller (GAPID), particle swarm optimized PID controller (PSO-PID), and proposed two-stage based PSO optimized fuzzy logic controller (TSO-FLC) is presented. The proposed fuzzy based controller is optimized at two stages: one is rule base optimization and other is scaling factor and gain factor optimization. This shows the best dynamic response following a step load change with different cases of bilateral contracts in deregulated environment. In addition, performance of proposed TSO-FLC is also examined for $\pm 30 \%$ changes in system parameters with different type of contractual demands between control areas and compared with GA-PID and PSO-PID. MATLAB/Simulink ${ }^{\circledR}$ is used for all simulations.
\end{abstract}

\section{Introduction}

Electrical power system is day by day gaining complexity due to stress to deliver quality power to consumers. Electrical energy is produced and consumed simultaneously and balance between demand and supply must be maintained in this complex scenario. This scenario is termed as automatic generation control (AGC). In interconnected power system, controlling frequency as well as tie line power is a challenge. After restructuring of power system where distribution and generation companies have the freedom to purchase and sell power in competitive energy market, demand and generation balance is treated as one of the ancillary services. Independent system operator (ISO) controls various ancillary services to provide secure, reliable, and economical power transmission. Distribution companies (DISCOs) and generation companies (GENCOs) are coordinating with each other under certain fixed contracts in normal operation. In interconnected multiarea power system, DISCO participation matrix (DPM) helps to visualize the various contracts made between GENCOs and DISCOs.
In interconnected power system, tie line flows and frequency being controlled and maintaining them at the scheduled values are the two main prime objectives of AGC. The change in frequency and tie line power flow together is termed as area control error (ACE) which is used as control input for AGC operation.

Researchers have exhaustively studied various aspects of AGC in deregulated scenario with different test conditions and control strategies [1-4]. Power system is categorized and modeled in terms of control areas for comprehensive analysis of AGC parameters. Literature available discusses single and multiarea model with and without deregulation aspects but, keeping in view of recent competitive energy market, it is also needed to be modeled with existing complexities, that is, nonlinearity present in the system to have better understanding and to have critical review of the system as a whole [5]. It is shown that governor dead band nonlinearity tends to produce a continuous oscillation in the frequency and tie line power transient response [6]. In deregulated era, power system had to undergo numerous technical challenges. In [7] Christie and Bose described several possible structures 
for AGC in deregulated scenario and also addressed technical issues in power system operation after deregulation. Two different approaches to AGC based on HVDC-link and ramp following controller are introduced by Bakken and Grande in [8] for Norway and Sweden interconnected power system in deregulated environment. A detailed simulation and optimization have been carried out by Donde et al. [9] for AGC system after deregulation. In their work, the concept of DISCO participation matrix has also been shown for different types of contracts and an optimized integral controller is proposed based on trajectory sensitivity.

The other approaches to handle AGC are in terms of various control strategies. There are classical and intelligent ways to address AGC but as complications are increasing with integration of renewable sources of energy, control solution will also be highly dynamic in nature. The classical control techniques alone are difficult to implement in a deregulated power system environment because of their fixed structure and it is difficult to determine satisfactory performance with varying operating point. With the advent of intelligence in control system, researchers are focusing on techniques which mix both the classical and intelligent approach. Roy et al. [10] studied the four-area multiunits AGC in restructured power system. A chaotic ant swarm optimization and real coded GA are used to obtain optimal gain parameters for optimal transient performances. Bhatt et al. [11] proposed model for AGC in restructured power system. The concept of DISCO participation matrix is used to simulate the bilateral contracts in the three and four areas. Hybrid particle swarm optimization is used to obtain optimal gain parameters for optimal transient performance. There are several control techniques based on optimal, intelligent, and robust approaches proposed for the AGC system in deregulated power systems in recent times.

Various optimization methods have been explored by researchers for PID controller in [12-15] but these conventional techniques have many limitations; therefore, intelligent techniques like fuzzy logic, neural networks, and so forth have gained popularity. Even fuzzy logic controller design suffers from proper selection of input and output variable's membership functions and rule base which give impetus to optimize fuzzy controller parameters. In general, these FLC parameters are determined by either experience or trial and error and this does not assure an optimal FLC design. Although many attempts have been made with several optimization methods in recent literature to optimize a fuzzy logic controller $[14,16,17]$, this paper presents a comparison between different control algorithms which are developed and implemented in the same model. The first control technique used is PID controller where gain parameters are optimized by genetic algorithm (GA-PID), second one also used PID controller where gain parameters are optimized by particle swarm optimization (PSO-PID), and the last approach is optimizing fuzzy controller in two different stages. Firstly, the rule base is optimized and later scaling and gain factors are optimized by particle swarm optimization (TSO-FLC).

The simulation results show that the TSO-FLC greatly reduces undershoot and settling time. Simulation results also show better performance of fuzzy controller even with $\pm 30 \%$ variation in system parameters.

\section{System Examined}

The two-area system model is considered in continuous operation mode and nominal system parameters used for study are given in Appendix. The schematic block diagram is shown in Figure 1. Each area is containing two GENCOs and two DISCOs. The contracts between GENCOs and DISCOs are shown in distribution participation matrix (DPM) $[18,19]$. $\mathrm{DPM}$ is also referred to as contract participation factor matrix (cpf_matrix). It makes the visualization of contracts. The number of rows indicates the number of GENCOs and the number of columns indicates the number of DISCOs. Here, the $i j$ th entry corresponds to the fraction of the total load power contracted by DISCO from $\mathrm{GENCO}_{i}[18]$.

The cpf_matrix is

$$
\begin{aligned}
& \text { cpf_matrix }=\left[\begin{array}{cccc}
\mathrm{cpf}_{11} & \mathrm{cpf}_{12} & \mathrm{cpf}_{13} & \mathrm{cpf}_{14} \\
\mathrm{cpf}_{21} & \mathrm{cpf}_{22} & \mathrm{cpf}_{23} & \mathrm{cpf}_{24} \\
\mathrm{cpf}_{31} & \mathrm{cpf}_{32} & \mathrm{cpf}_{33} & \mathrm{cpf}_{34} \\
\mathrm{cpf}_{41} & \mathrm{cpf}_{42} & \mathrm{cpf}_{43} & \mathrm{cpf}_{44}
\end{array}\right] \text {, } \\
& \text { where, } \sum_{j} \mathrm{cpf}_{i j}=1 \text {. }
\end{aligned}
$$

The system output, which depends on the area control error (ACE), is

$$
\mathrm{ACE}_{i}=\Delta P_{\mathrm{tie}, i}+b_{i} \Delta f_{i},
$$

where $b_{i}$ is frequency bias constant, $\Delta f$ frequency deviation, and $\Delta P_{\text {tie }}$ change in tie line power.

The coefficients that distribute area control error (ACE) to several GENCOs are termed as ACE participation factors (apf) and for an integrated power system it is shown in apf_matrix, as shown in

$$
\text { apf_matrix }=\left[\begin{array}{cccc}
\operatorname{apf}_{1} & 0 & 0 & 0 \\
0 & \mathrm{apf}_{2} & 0 & 0 \\
0 & 0 & \mathrm{apf}_{3} & 0 \\
0 & 0 & 0 & \mathrm{apf}_{4}
\end{array}\right],
$$

where additions of all apfs are equal to 1, within control area

$$
\sum_{i} \operatorname{apf}_{i}=1
$$

The contracted scheduled loads in DISCOs in Area 1 are $\Delta P_{\mathrm{Ld} 1_{\text {Cont }}}$ and $\Delta P_{\mathrm{Ld} 2_{\text {Cont }}}$ and in Area 2 are $\Delta P_{\mathrm{Ld} 3_{\text {Cont }}}$ and $\Delta P_{\mathrm{Ld} 4_{\text {Cont }}}$ and represented in the $\Delta P_{\mathrm{LD}_{\text {Cont }}}$ matrix. The uncontracted local loads in Area 1 are $\Delta P_{\mathrm{Ld} 1_{\text {Uncont }}}$ and $\Delta P_{\mathrm{Ld} 2_{\text {Uncont }}}$ whereas Area 2 are $\Delta P_{\text {Ld3_Uncont }}$ and $\Delta P_{\text {Ld4_Uncont }}$ shown in $\Delta P_{\text {LD_Uncont }}$ matrix [11]

$$
\Delta P_{\text {LD_Cont }}=\left[\begin{array}{l}
\Delta P_{\text {Ld1_Cont }} \\
\Delta P_{\text {Ld2_Cont }} \\
\Delta P_{\mathrm{Ld} 3 \text { _Cont }} \\
\Delta P_{\mathrm{Ld} 4 \text { _Cont }}
\end{array}\right]
$$




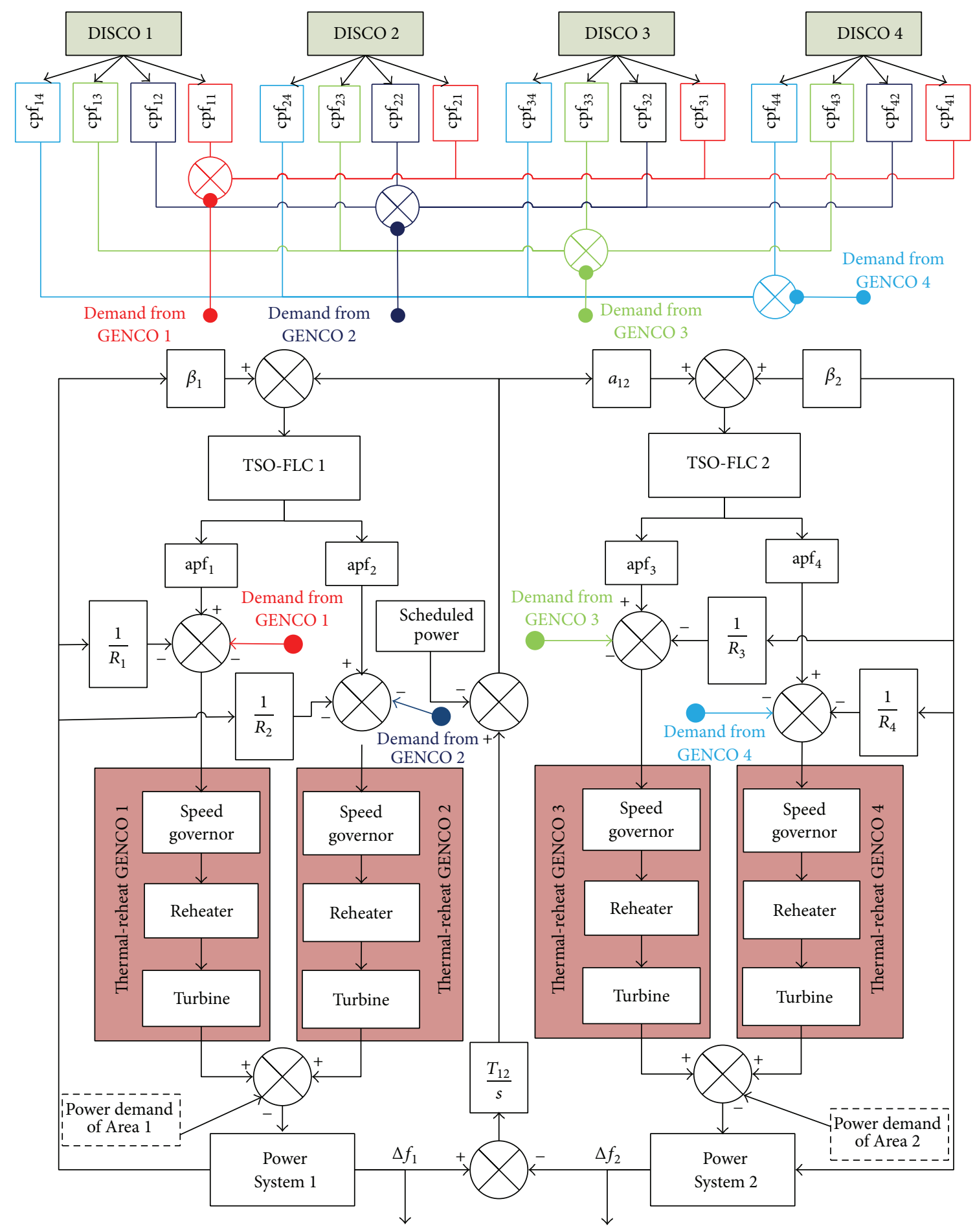

FIGURE 1: Block diagram representing a two-area interconnected power system.

$$
\Delta P_{\text {LD_Uncont }}=\left[\begin{array}{c}
\Delta P_{\text {Ld1_Uncont }} \\
\Delta P_{\text {Ld2_Uncont }} \\
\Delta P_{\text {Ld3_Uncont }} \\
\Delta P_{\text {Ld4_Uncont }}
\end{array}\right] .
$$

The total distributed power by $j$ th DISCO,

$$
\Delta P_{\mathrm{Ld}(j)}=\Delta P_{\mathrm{Ld}(j)_{-} \text {Cont }}+\Delta P_{\mathrm{Ld}(j)_{-} \text {Uncont }},
$$

where $\Delta P_{\mathrm{Ld}(j) \text { Cont }}$ is contracted can be shown through cpf_matrix but uncontracted power for $j$ th DISCO is out of scope of cpf_matrix. 


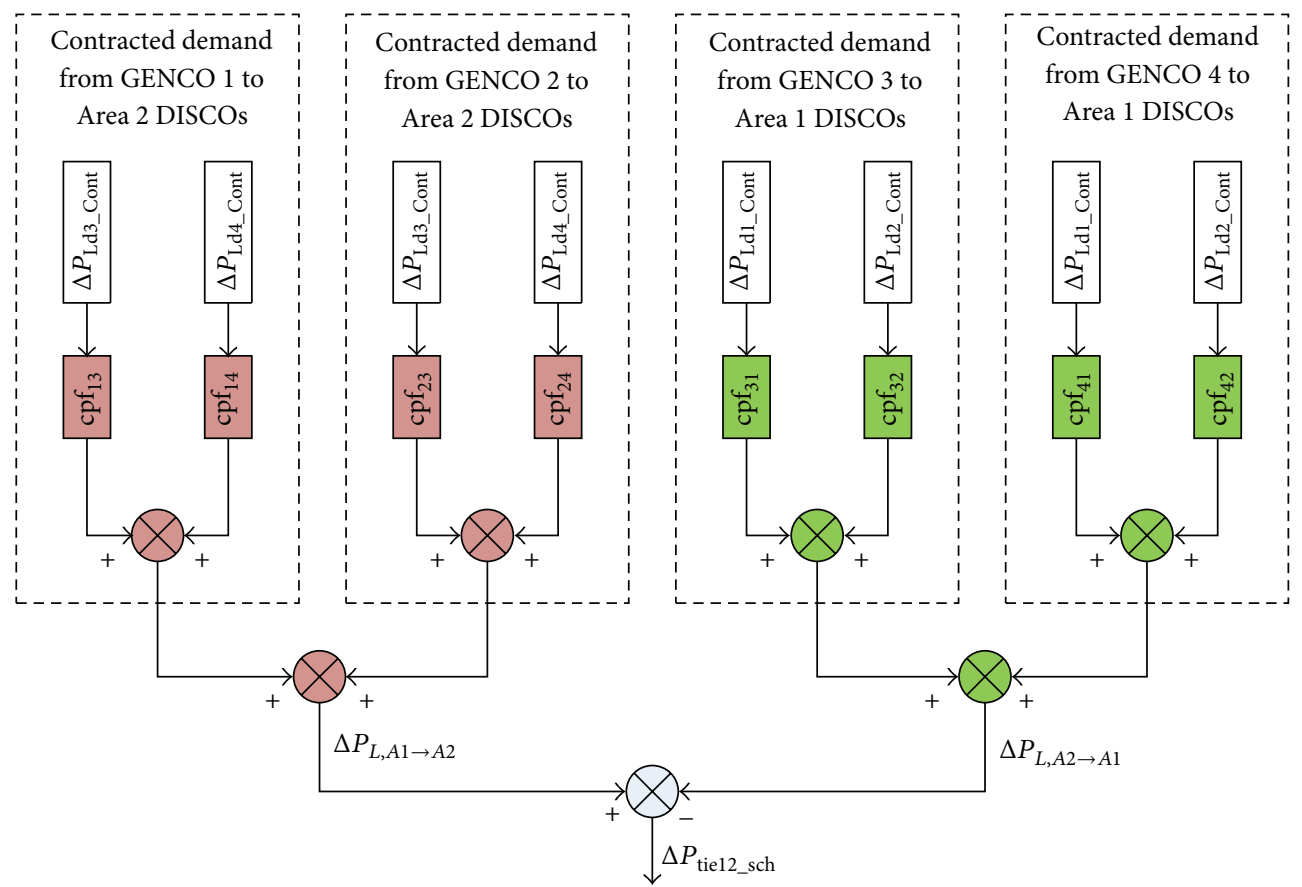

Figure 2: The block diagram representation of scheduled_ $P_{\text {tiel2 }}$.

The total distributed power shown in matrix $\Delta P_{\mathrm{LD}}$ is

$$
\Delta P_{\text {LD }}=\Delta P_{\text {LD_Cont }}+\Delta P_{\text {LD_Uncont }} .
$$

Similar to this, total generated powers through GENCOs in Area 1 are $\Delta P_{g 1}$ and $\Delta P_{g 2}$ and in Area 2 are $\Delta P_{g 3}$ and $\Delta P_{g 4}$ and these are shown in the $\Delta P_{G}$ matrix.

The contracted generated powers in Area 1 are $\Delta P_{g 1 \_ \text {Cont }} \& \Delta P_{g 2_{2} \text { Cont }}$ and in Area 2 are $\Delta P_{\text {g3_Cont }} \& \Delta P_{\text {g4_Cont }}$ shown in $\Delta P_{G_{-} \text {Cont }}$ matrix

$$
\Delta P_{\text {G_Cont }}=\left[\begin{array}{l}
\Delta P_{g 1 \_C o n t} \\
\Delta P_{g 2 \_C o n t} \\
\Delta P_{g 3 \_ \text {Cont }} \\
\Delta P_{g 4 \_C o n t}
\end{array}\right] .
$$

The uncontracted powers demanded under contract violation required in Area 1 and Area 2 are referred to as $\Delta P_{L 1, \mathrm{LOC}}$ and $\Delta P_{L 2, \mathrm{LOC}}$ is required power by local GENCOs only in that area. That required power from GENCOs shown in $\Delta P_{G \text { Uncont }}$ matrix

$$
\Delta P_{\text {G_Uncont }}=\left[\begin{array}{l}
\Delta P_{g 1 \_ \text {Uncont }} \\
\Delta P_{g 2 \_ \text {Uncont }} \\
\Delta P_{g 3 \_ \text {Uncont }} \\
\Delta P_{g 4 \_ \text {Uncont }}
\end{array}\right],
$$

where $\Delta P_{g 1 \_ \text {Uncont }}$ and $\Delta P_{g 2_{2} \text { Uncont }}$ are uncontracted required power from GENCO 1 and GENCO 2 in Area 1 and $\Delta P_{g 3 \text { Uncont }}$ and $\Delta P_{\text {g4_Uncont }}$ are uncontracted required power from GENCO 3 and GENCO 4 in Area 2

$$
\Delta P_{L(k), \text { LOC }}=\sum_{i} \Delta P_{g(i) \_ \text {Uncont }},
$$

where $i$ referred to GENCOs within $k$ th control area.
And $\Delta P_{g(i) \_ \text {Uncont }}$ is calculated from equation

$$
\Delta P_{g(i)_{-} \text {Uncont }}=\operatorname{apf}_{i} * \sum_{j} \Delta P_{\mathrm{Ld}(j) \_ \text {Uncont }} .
$$

Or, in matrix form,

$$
\Delta P_{G_{-} \text {Uncont }}=\text { apf_matrix } * \Delta P_{\text {LD_Uncont }} .
$$

So, total required generation power in matrix form is represented as

$$
\begin{aligned}
& \Delta P_{G}=\Delta P_{G_{-} \text {Cont }}+\Delta P_{G_{-} \text {Uncont }}, \\
& \Delta P_{G}=\mathrm{cpf}_{\text {matrix }} * \Delta P_{\text {LD_Cont }_{\text {_Conf }}}+\operatorname{apf}_{\text {matrix }} * \Delta P_{\text {LD_Uncont }} .
\end{aligned}
$$

The total generation required of individual GENCOs can be calculated also from equation

$$
\begin{aligned}
\Delta P_{g(i)}= & \sum_{j}\left(\operatorname{cpf}_{i j} * \Delta P_{\mathrm{Ld}(j)_{2} \text { Cont }}\right)+\operatorname{apf}_{i} \\
& * \sum_{j} \Delta P_{\mathrm{Ld}(j)_{\text {_Uncont }}} .
\end{aligned}
$$

So, total demanded power from GENCOs is shown in $\Delta P_{G}$ matrix

$$
\Delta P_{G}=\left[\begin{array}{c}
\Delta P_{g 1} \\
\Delta P_{g 2} \\
\Delta P_{g 3} \\
\Delta P_{g 4}
\end{array}\right] .
$$

The scheduled tie line power flow between Areas 1 and 2 shown in block diagram in Figure 2 can be represented by

$$
\begin{aligned}
& \Delta P_{\text {tiel2_sch }}=\left(\operatorname{cpf} 13 * \Delta P_{\mathrm{Ld} 3_{\text {Cont }}}+\operatorname{cpf} 23 * \Delta P_{\text {Ld3_Cont }}\right. \\
& \left.\quad+\operatorname{cpf} 14 * \Delta P_{\text {Ld4_Cont }}+\operatorname{cpf} 24 * \Delta P_{\text {Ld4_Cont }}\right)
\end{aligned}
$$


TABLE 1: PID controller gains from optimization method.

\begin{tabular}{llccc}
\hline S. no. & & Area 1 PID gains & Area 2 PID gains \\
\hline \multirow{2}{*}{1} & GA optimized & $K_{p}$ & 0.59226 & 1.00299 \\
& PID controller gains & $K_{i}$ & 0.73350 & 0.84666 \\
& $K_{d}$ & 0.62571 & 0.45060 \\
\hline \multirow{2}{*}{2} & $K_{p}$ & 0.67927 & 0.95495 \\
& \multirow{2}{*}{ PSO optimized } & $K_{i}$ & 1.60343 & 1.72912 \\
& PID controller gains & $K_{d}$ & 0.96307 & 0.78236 \\
\hline
\end{tabular}

$$
\begin{aligned}
& -\left(\operatorname{cpf} 31 * \Delta P_{\mathrm{Ld} 1 \_C o n t}+\operatorname{cpf} 41 * \Delta P_{\mathrm{Ld} 1 \_C o n t}\right. \\
& \left.+\operatorname{cpf} 32 * \Delta P_{\mathrm{Ld} 2 \text { _Cont }}+\operatorname{cpf} 42 * \Delta P_{\mathrm{Ld} 2 \_C o n t}\right)
\end{aligned}
$$

\section{Control Strategies}

In this paper, two different control strategies are explored. The first control strategy is conventional proportional-integralderivative (PID) control and another is artificial intelligence based fuzzy logic control (FLC). PID controller is optimized by two different stochastic optimization techniques GA and PSO and later PSO based optimized FLC is proposed, where FLC parameters are optimized in two different stages.

3.1. PID Controller. PID controller is selected as controller for AGC and GA and PSO are used for optimizing of gain parameters, that is, $K_{p}, K_{i}$, and $K_{d} . \mathrm{ACE}_{i}$ is selected as controller input and $U_{\text {PID }}$ is output of controller as given in

$$
\begin{aligned}
U_{\mathrm{PID}}= & K_{p}\left(\mathrm{ACE}_{i}\right)+K_{i}\left(\int \mathrm{ACE}_{i} d t\right) \\
& +K_{d}\left(\frac{d \mathrm{ACE}_{i}}{d t}\right) .
\end{aligned}
$$

3.1.1. Genetic Algorithm. The genetic algorithm (GA) is inspired by the principles of genetics and evolution. It mimics the reproduction behavior observed in biological populations. The GA employs the principle of "survival of the fittest" in its search process to select and generate individuals that are adapted to their environment. Therefore, over a number of generations, desirable traits will evolve and remain in the genome composition of the population over traits with weaker undesirable characteristics. The GA is well suited to and has been extensively applied to solve complex design optimization problems because it can handle both discrete and continuous variables and nonlinear objective and constrained functions without requiring gradient information [13, 15-17]. The AGC modeled has an objective function for PID optimization as given in (18) which is aimed for minimization of peak undershoots and settling time of frequency and tie line deviation

$$
\begin{aligned}
J_{\mathrm{OBJ}} & =\int_{0}^{T}\left(\lambda\left(\left|\mathrm{PU}_{\Delta f_{1}}\right|+\left|\mathrm{PU}_{\Delta f_{2}}\right|+\mu\left|\mathrm{PU}_{\Delta P_{\text {tiel2 }} \mid}\right|\right)\right. \\
& \left.+\left(\mathrm{ST}_{\Delta f_{1}}+\mathrm{ST}_{\Delta f_{2}}+\mathrm{ST}_{\Delta P_{\text {tie12 }}}\right)\right) d t .
\end{aligned}
$$

Here, $\lambda, \mu$, and $T$ are selected as 10, 500, and 50, respectively.

3.1.2. Particle Swarm Optimization. Particle swarm optimization (PSO) is a heuristic search method which is by the swarming or collaborative behavior of biological populations. In PSO, a set of randomly generated solutions (initial swarm) propagates in the design space towards the optimal solution over a number of iterations (moves) based on large amount of information about the design space, that is, assimilated and shared by all members of the swarm. PSO is inspired by the ability of flocks of birds, schools of fish, and herds of animals to adapt to their environment, find rich sources of food, and avoid predators by implementing an "information sharing" approach, hence, developing an evolutionary advantage. Its ability to converge faster to global solution makes it favorable technique compared to other stochastic optimization methods like GA and simulated annealing (SA) [17-19]. The PID controller gains for both control areas optimized by GA and PSO are shown in Table 1. An algorithm is developed for the system under study for optimization with PSO and following steps are followed.

Algorithm steps for PSO implementation are given below:

(1) Setting parameters for PSO:

(a) Define dimensions of search space.

(b) Define boundaries of search space (minimum and maximum values of variables).

(c) Define minimum and maximum values of particle's velocities.

(2) Initialize population:

(a) Initialize random population of swarm within boundaries. 

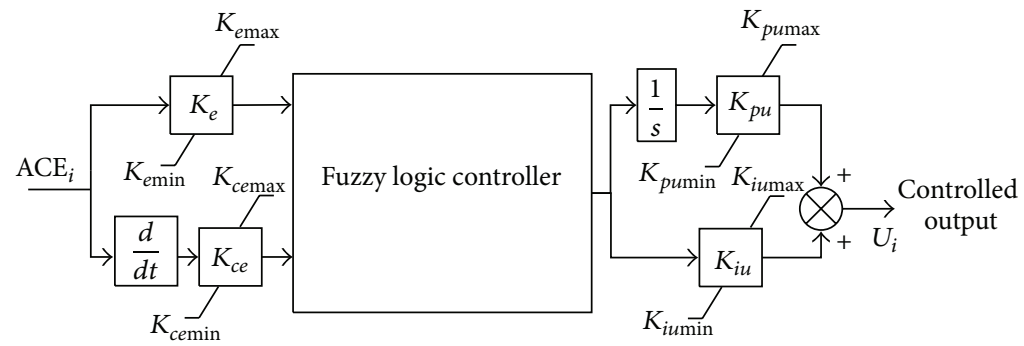

FIGURE 3: MISO-type fuzzy logic controller.

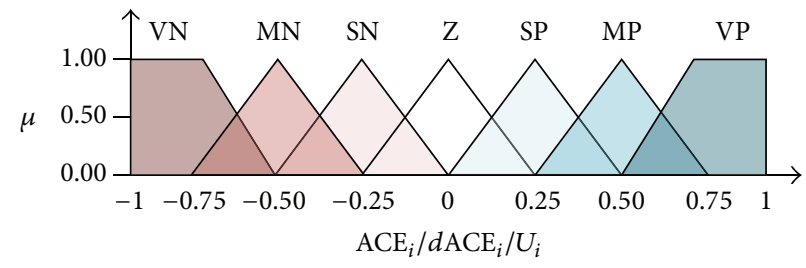

FIGURE 4: Membership functions of inputs and output variable.

(b) Set random velocities to particles of swarm within boundaries.

(3) Evaluate the fitness of each particle position as per objective function selected:

(a) Identify each particle's best known position.

(b) Identify the best known position of swarm.

(c) Update the velocities and positions of particles.

(4) Repeat step (3) up to either maximum iterations or convergence criteria satisfied.

3.2. PSO Optimized Fuzzy Logic Controller. Power system operation and control have undergoing immense changes from earlier times as complexity has increased multifold due to stress to deliver quality and uninterrupted power to consumers. These reasons have boosted power system engineers to use intelligent control strategies in operation and control where fuzzy logic has gained popularity amongst others because of its computing approach based on "degrees of truth" rather than the usual "true or false." Therefore, it is widely used in engineering problems. Fuzzy set theory and fuzzy logic establish the rules of a nonlinear mapping. The fuzzy logic controller modeling consists of three steps of fuzzification, determination of fuzzy control rules, and defuzzification [20]. Fuzzy logic is a systematic and easier way to implement control algorithm for uncertain and indefinite models in engineering and suits most AGC problem [21, 22].

The comparison between the proposed TSO-FLC and GA-PID and PSO-PID controllers is quantified based on two dynamic performance indices, that is, peak undershoot and settling time.
TABle 2: Fuzzy rules for Area 1 controller.

\begin{tabular}{ccccccccc}
\hline & \multicolumn{8}{c}{ ACE } \\
& & VN & MN & SN & Z & SP & MP & VP \\
\hline \multirow{4}{*}{$\Delta$ ACE } & VN & VN & VN & VN & SN & MN & SN \\
& MN & VN & MN & SN & MN & VN & SN & SP \\
& SN & VN & VN & VN & VN & Z & Z & Z \\
& Z & MN & MN & N & Z & MP & MP & MP \\
& SP & Z & Z & Z & VP & VP & VP & VP \\
& MP & SN & SP & VP & MP & SP & MP & VP \\
VP & SP & MP & SP & VP & VP & VP & VP \\
\hline
\end{tabular}

The multi-input and single-output (MISO) type fuzzy controller is shown in Figure 3. $K_{p u}$ and $K_{i u}$ are the proportional and integral gains, respectively. Two inputs, $\mathrm{ACE}_{i}$ and derivative of $\mathrm{ACE}_{i}$, that is, $\left(d \mathrm{ACE}_{i} / d t\right)$, are fed to the fuzzy controller. The fuzzy logic process is initiated by fuzzification of $\mathrm{ACE}_{i}$ and $d \mathrm{ACE}_{i} / d t$. Mamdani fuzzy inference mechanism and centroid method for defuzzification are later used for respective processes. $U_{i}$ is a crisp value and $u_{i}$ is a control signal for the system

$$
u_{i}=-K_{p u} U_{i}-K_{i u} \int U_{i} d t .
$$

Membership functions (MF) specify the degree to which a given input belongs to a set. FLC has used seven membership functions, Very Negative (VN), Medium Negative (MN), Small Negative (SN), Zero (Z), Small Positive (SP), Medium Positive (MP), and Very Positive (VP). The membership function sets of FLC for input as well as output variables are shown in Figure 4. Optimized rule base for proposed TSOFLC for both areas is shown in Tables 2 and 3. 


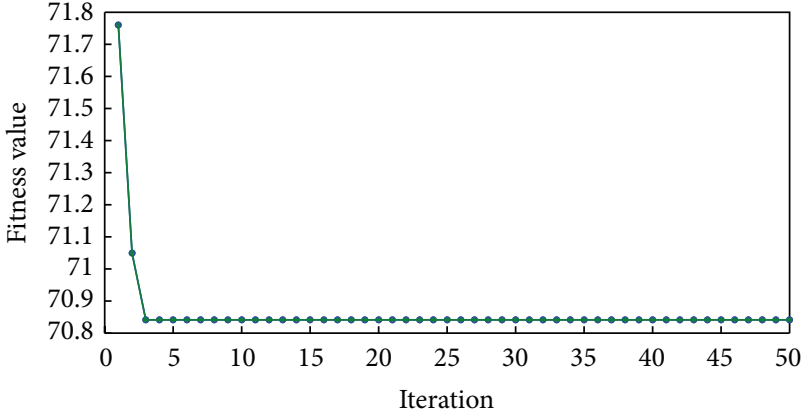

Figure 5: FLC optimization of step 1 for rule base optimization.

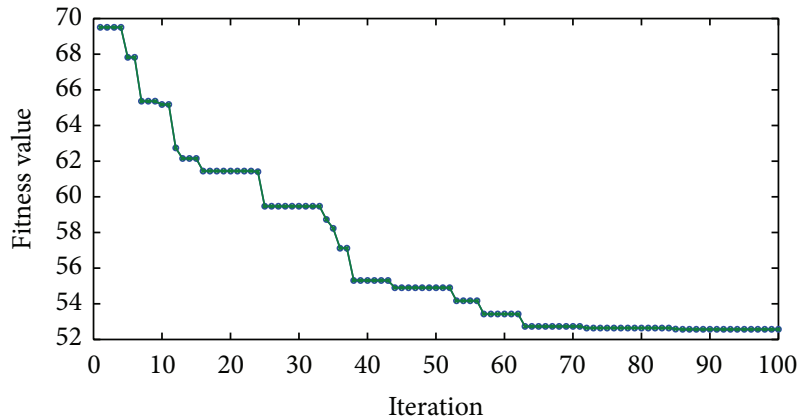

Figure 6: FLC optimization of step 2 for scaling and gain factor optimization.

TABLE 3: Fuzzy rules for Area 2 controller.

\begin{tabular}{ccccccccc}
\hline & & \multicolumn{9}{c}{ ACE } \\
& & VN & MN & SN & Z & SP & MP & VP \\
\hline \multirow{4}{*}{$\Delta$ ACE } & VN & VN & MN & VN & SN & SN & Z \\
& MN & VN & VN & VN & VN & SN & Z & Z \\
& SN & VN & VN & VN & MN & SN & SP & SP \\
& Z & MN & MN & VN & Z & VP & MP & MP \\
& SP & SN & SN & SP & MP & VP & VP & VP \\
& MP & Z & Z & SP & VP & VP & VP & VP \\
VP & Z & SP & SP & VP & MP & VP & VP \\
\hline
\end{tabular}

TABLE 4: Optimized scaling and gain parameters for TSO-FLC.

\begin{tabular}{lcccc}
\hline & \multicolumn{2}{c}{ Scaling parameters } & \multicolumn{2}{c}{ Gain parameters } \\
& $K_{e}$ & $K_{c e}$ & $K_{p u}$ & $K_{i u}$ \\
\hline FLC for Area 1 & 1.12833 & 0.93282 & 1.43489 & 2.18240 \\
FLC for Area 2 & 1.88194 & 0.56237 & 0.56237 & 2.10918 \\
\hline
\end{tabular}

The membership functions of each input and each output are spread across a linear distribution range from -1 to +1 . In two stages FLC is optimized by PSO with objective function given in (18).

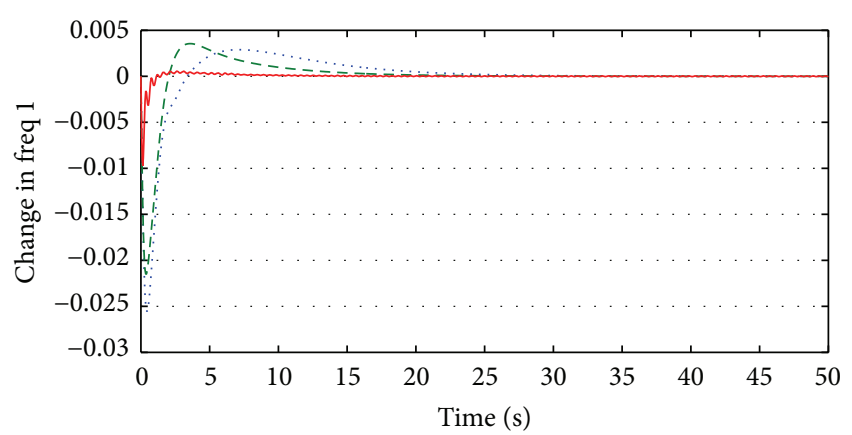

GA-PID

- . - PSO-PID

- TSO-FLC

(a)

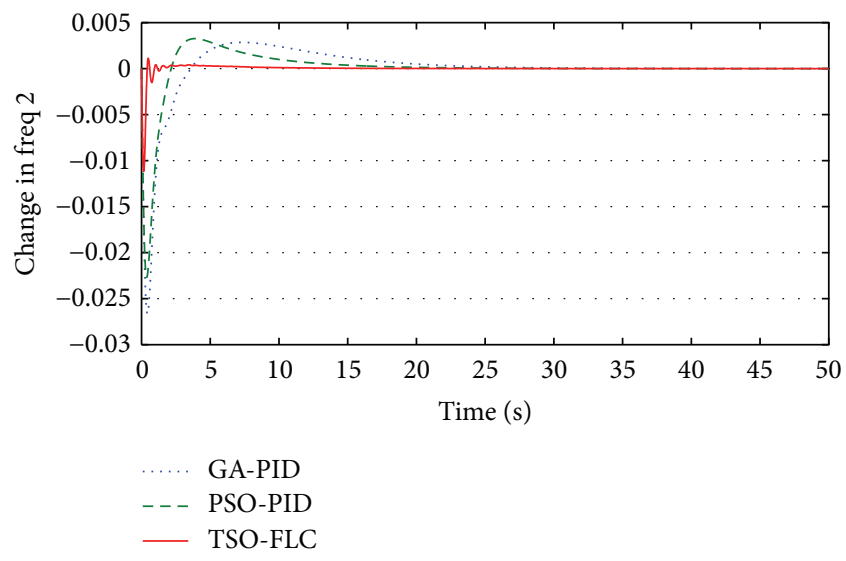

(b)

FIGURE 7: Comparison of GA-PID, PSO-PID, and TSO-FLC for reheat type two-area thermal power system (Case A): Poolco (a) frequency deviation in Area 1 and (b) frequency deviation in Area 2.

Rule Base Optimization. In this step, apart from center rule, all other rules need to be optimized. Only one rule is configured that when both inputs are zero then output is also zero. In system under study, out of 49 rules, 48 rules are required to be optimized. The curve between best fitness values with respect to iteration for rule base optimization is shown in Figure 5.

Scaling Factor and Gain Optimization. In this second step, optimum values of two scaling factors $\left(K_{e}\right.$ and $\left.K_{c e}\right)$ and two gain parameters $\left(K_{p u}\right.$ and $\left.K_{i u}\right)$ are needed to be optimized of FLC. Graphically the best fitness values with respect to iteration are represented in Figure 6. Table 4 shows the optimized scaling and gain parameters for TSO-FLC.

\section{Test Cases and Simulations}

There are three different test cases of deregulated power system considered for justification of optimum performance of proposed TSO-FLC controller as compared to conventional GA-PID and PSO-PID controllers. These test cases are Poolco based transactions, combination of Poolco and bilateral based 
TABLE 5: Different test cases for proposed system.

\begin{tabular}{|c|c|c|c|c|c|c|c|c|c|}
\hline Test cases & & cpf_ma & atrix & & $\begin{array}{l}\text { Contracted } \\
\text { load (p.u.) } \\
\left(\Delta P_{\text {LD_Cont }}\right)\end{array}$ & $\begin{array}{l}\text { Uncontracted } \\
\text { load (p.u.) } \\
\left(\Delta P_{\mathrm{LD}_{\text {Uncont }}}\right)\end{array}$ & $\begin{array}{l}\text { Load } \Delta P_{\mathrm{LD}} \\
\quad \text { (p.u.) }\end{array}$ & $\begin{array}{c}\text { Scheduled } \\
\text { GENCOs } \\
\text { power (p.u.) } \\
\left(\Delta P_{G}\right) \\
\end{array}$ & $\begin{array}{l}\text { Scheduled tie } \\
\text { line power } \\
\text { flow (p.u. }) \\
\left(\Delta P_{\text {tiel2_sch }}\right) \\
\end{array}$ \\
\hline \multirow{4}{*}{$\begin{array}{l}\text { Case A } \\
\text { (Poolco based transactions) }\end{array}$} & & 0.5 & $0 \quad 0$ & & 0.01 & 0.00 & 0.01 & 0.01 & \multirow{4}{*}{0} \\
\hline & 0.5 & 0.5 & $0 \quad 0$ & & 0.01 & 0.00 & 0.01 & 0.01 & \\
\hline & 0 & $\begin{array}{ll}0 & 0\end{array}$ & $0.5 \quad 0.5$ & & 0.01 & 0.00 & 0.01 & 0.01 & \\
\hline & 0 & 0 & 0.50 .5 & & [0.01 & {$[0.00]$} & [0.01] & {$[0.01]$} & \\
\hline \multirow{4}{*}{$\begin{array}{l}\text { Case B } \\
\text { (combination of Poolco and } \\
\text { bilateral based } \\
\text { transactions) }\end{array}$} & 0.25 & 0.20 & 0.25 & & 0.01 & $0.00]$ & 0.01 & $0.0070]$ & \multirow{4}{*}{-0.0085} \\
\hline & 0.25 & 0.20 & 0 & & 0.01 & 0.00 & 0.01 & 0.0045 & \\
\hline & 0.50 & 0.30 & 0.15 & & 0.01 & 0.00 & 0.01 & 0.0095 & \\
\hline & 0 & 0.30 & 0.60 & $1]$ & 0.01 & {$[0.00$} & [0.01 & 0.0190 & \\
\hline \multirow{4}{*}{$\begin{array}{l}\text { Case C } \\
\text { (contract violation) }\end{array}$} & 0.25 & 0.20 & 0.25 & & 0.01 & $0.000]$ & 0.010 & $0.0090]$ & \multirow{4}{*}{-0.0085} \\
\hline & 0.25 & 0.20 & 0 & & 0.01 & 0.004 & 0.014 & 0.0065 & \\
\hline & 0.50 & 0.30 & 0.15 & & 0.01 & 0.000 & 0.010 & 0.0135 & \\
\hline & [ & 0.30 & 0.60 & $1]$ & {$[0.01]$} & {$[0.008$} & [0.018 & {$[0.0230$} & \\
\hline
\end{tabular}

TABLE 6: System parameters.

Rated power (Area 1 and Area 2)

Transfer function gain of generator (Area 1 and Area 2)

Generator's time constant (Area 1 and Area 2)

Governor's time constant

Governor's time constant

Steam turbine's time constant

Regulation of the governor (Area 1 and Area 2)

Frequency bias constant

Synchronizing power coefficient

Synchronization coefficient

$\begin{array}{cc}P_{r 1} \text { and } P_{r 2} & 2000 \mathrm{MW} \\ K_{p 1} \text { and } K_{p 2} & 120 \\ T_{p 1} \text { and } T_{p 2} & 20 \\ T_{g 1} & 0.08 \\ T_{g 2} & 0.02 \\ T_{t} & 0.3 \\ R_{1} \text { and } R_{2} & 2.4 \\ \beta & 0.425 \\ a_{12} & 1 \\ T_{12} & 0.545\end{array}$

transactions, and contract violation. The cpf_matrix and load power from each DISCO are varied in each test case as depicted in Table 5. Apart from this all GENCOs are allowed to participate equally in each area for AGC; therefore, ACE participation factor $\left(\mathrm{apf}_{i}\right) 0.5$ is considered for simulation purpose.

The total generated power $\Delta P_{g(i)}$ required by individual GENCO is composed of all contracted and uncontracted loads. Each GENCO shares the uncontracted load of its own control area according to its ACE participation factor. The values of system parameters given in Appendix (Table 6) are used for a comparative study. Frequency deviations of both areas and tie line deviation after load change as per load distribution (Table 5) in each area for test cases A, B, and C are shown in Figures 7, 8, and 9, respectively. Two performance indices (settling time and peak undershoot) were selected for justification of dynamic performance response of controllers. Effect of $+30 \%$ and $-30 \%$ change in parameter values $\beta, T_{12}$, and $T_{p}$ (parameters value in Table 7 in Appendix) is also examined. Peak undershoot and settling time of both areas and tie line deviation are also determined with $+30 \%$ and $-30 \%$ change in system parameters in each area for test cases 


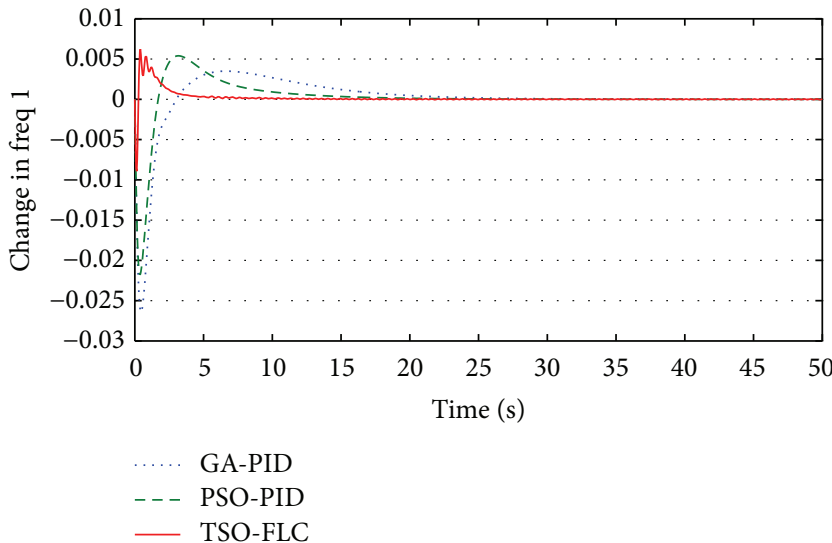

(a)

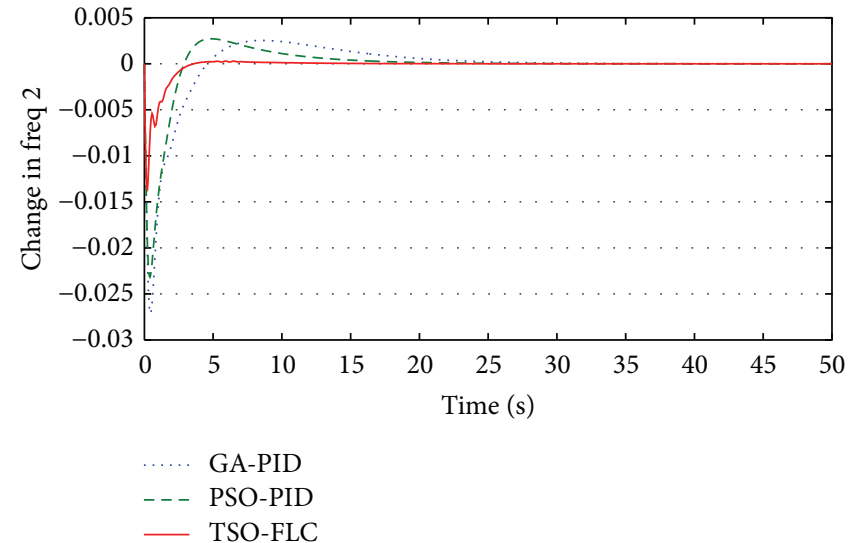

(b)

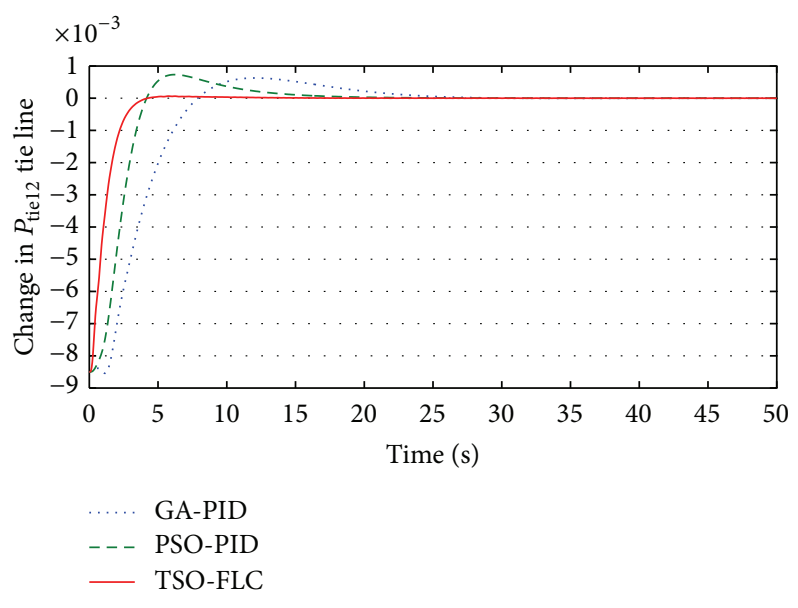

(c)

Figure 8: Comparison of GA-PID, PSO-PID, and TSO-FLC for reheat type two-area thermal power system (Case B). Combination of Poolco and bilateral contracts: (a) frequency deviation in Area 1, (b) frequency deviation in Area 2, and (c) tie line power deviation.

TABLE 7: Different cases with different system parameters.

\begin{tabular}{lccc}
\hline & $T_{p}$ & $\beta$ & $T_{12}$ \\
\hline Case 1 (nominal value) & 20 & 0.425 & 0.545 \\
Case 2 (+30\% increase) & 26 & 0.5525 & 0.7085 \\
Case 3 (-30\% decrease) & 14 & 0.2975 & 0.3815 \\
\hline
\end{tabular}

$\mathrm{A}, \mathrm{B}$, and $\mathrm{C}$ shown in Figures $10,11,12,13,14$, and 15 . The comparison of dynamic performances of GA-PID and PSOPID controllers with the proposed TSO-FLC controller shows that proposed TSO-FLC gives better results in terms of lesser settling time and peak undershoot. Matlab/Simulink is used for simulation purpose.

In order to examine the performance of controllers, peak undershoot and settling time of both areas and tie line deviation are determined for test cases $A, B$, and $C$ with standard values of system parameters. Apart from this the effect of $+30 \%$ and $-30 \%$ change in parameter values $\beta$, $T_{12}$, and $T_{p}$ (parameters value in Table 7 ) is also examined, so further performance indices for $+30 \%$ and $-30 \%$ change in system parameters for different test cases determined are shown in Figures 10, 11, 12, 13, 14, and 15. Based on this comparison, it can be concluded that proposed TSO-FLC gives better results in terms of lesser settling time and peak undershoot compared to GA-PID and PSO-PID controllers.

\section{Conclusion}

In this paper, an optimization strategy for FLC is proposed for AGC. This optimization strategy is based on rule base optimization and scaling factor and gain factor optimization of FLC. PSO is used as optimization technique. The performance of proposed controller is compared with conventional PID controller also optimized by two optimization methods GA and PSO under different test cases based on contractual 


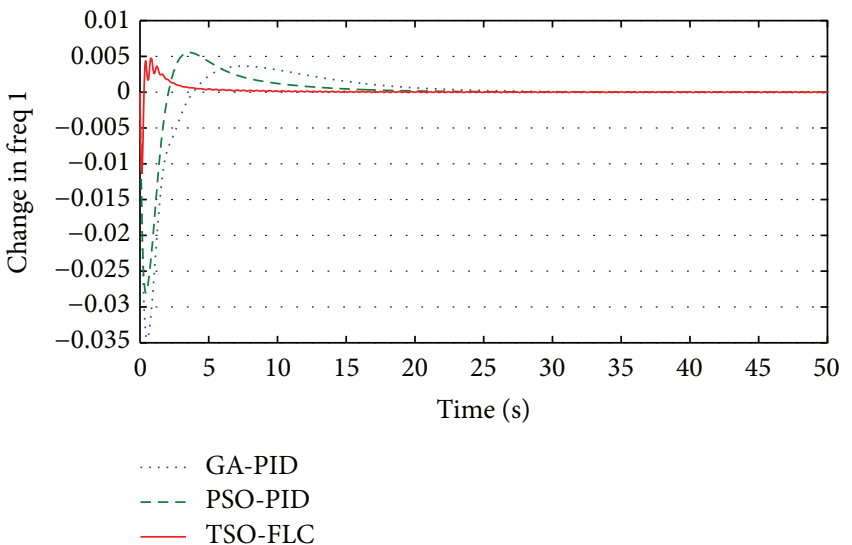

(a)

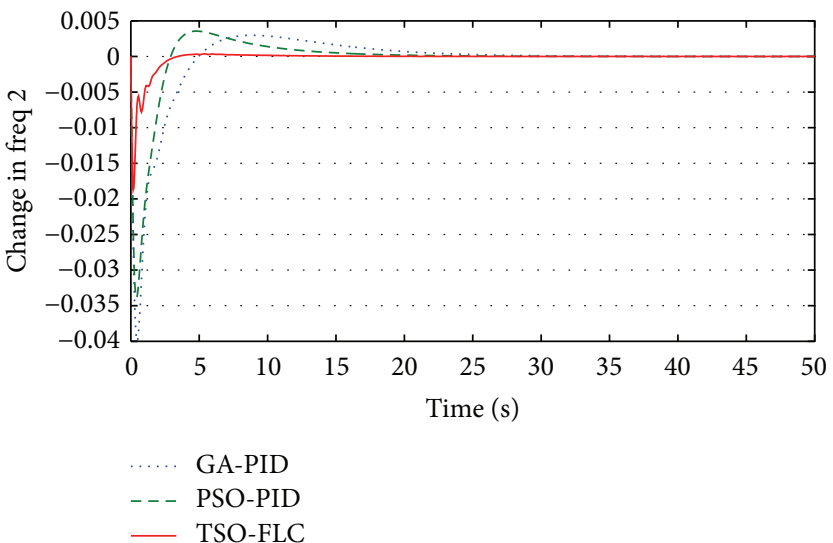

(b)

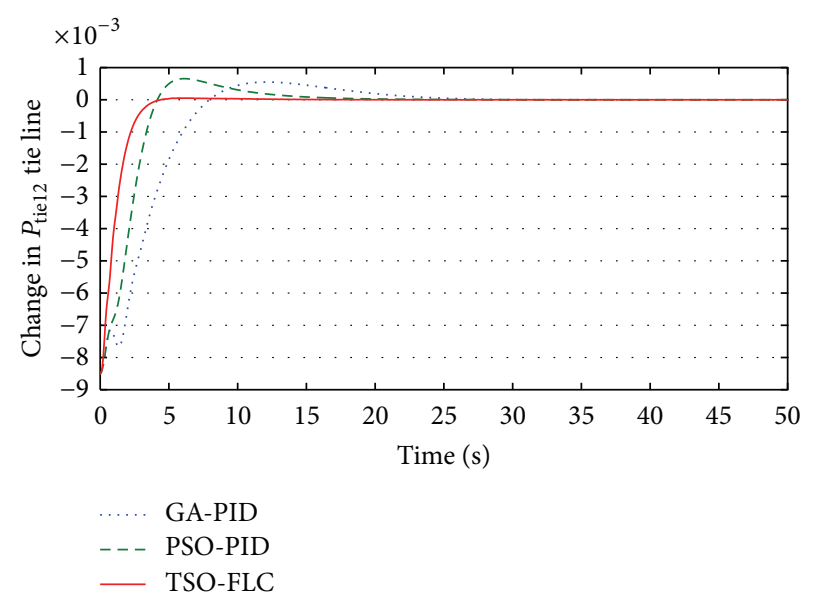

(c)

FIGURE 9: Comparison of GA-PID, PSO-PID, and TSO-FLC for reheat type two-area thermal power system (Case C). Contract violation: (a) frequency deviation in Area 1, (b) frequency deviation in Area 2, and (c) tie line power deviation.

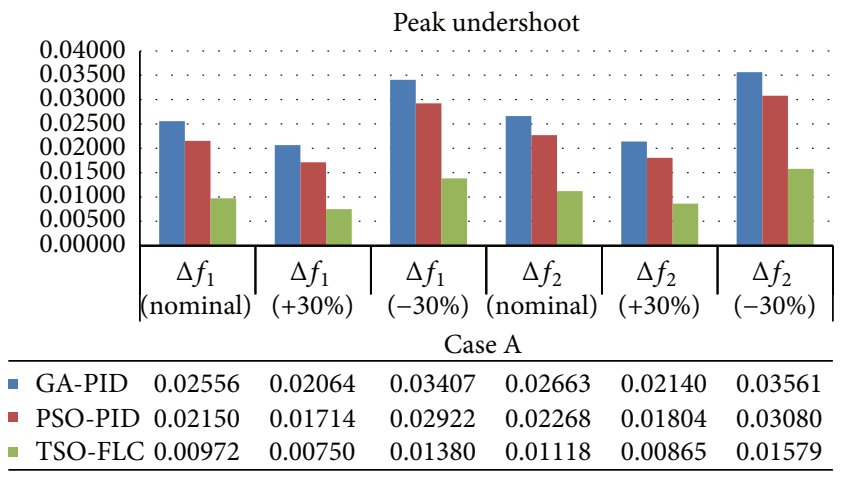

Figure 10: Peak undershoot comparison at $\pm 30 \%$ variation in system parameters for Case A.

demands in deregulated power system. The dynamic performance of proposed controllers is observed on the basis of two performance indices, that is, settling time and peak

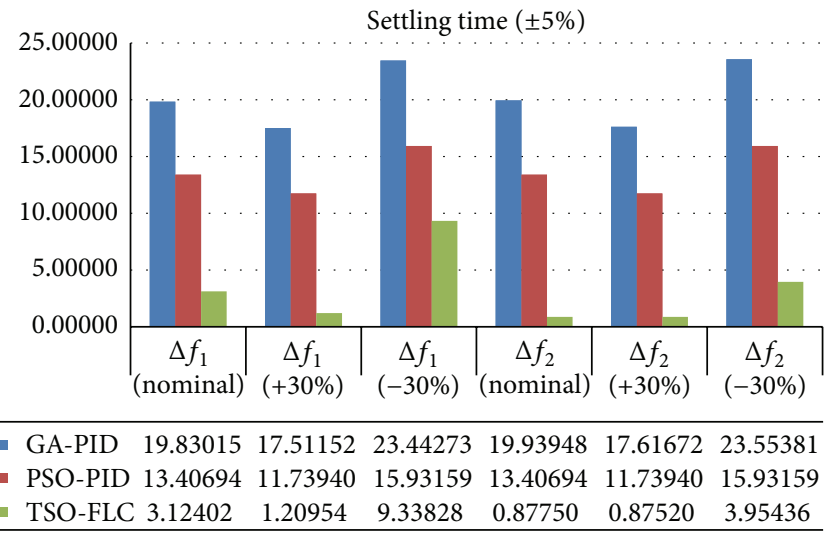

FIGURE 11: Settling time comparison at $\pm 30 \%$ variation in system parameters for Case A.

undershoot. Simulation results show that proposed TSO-FLC controller provides a better performance in comparison of 


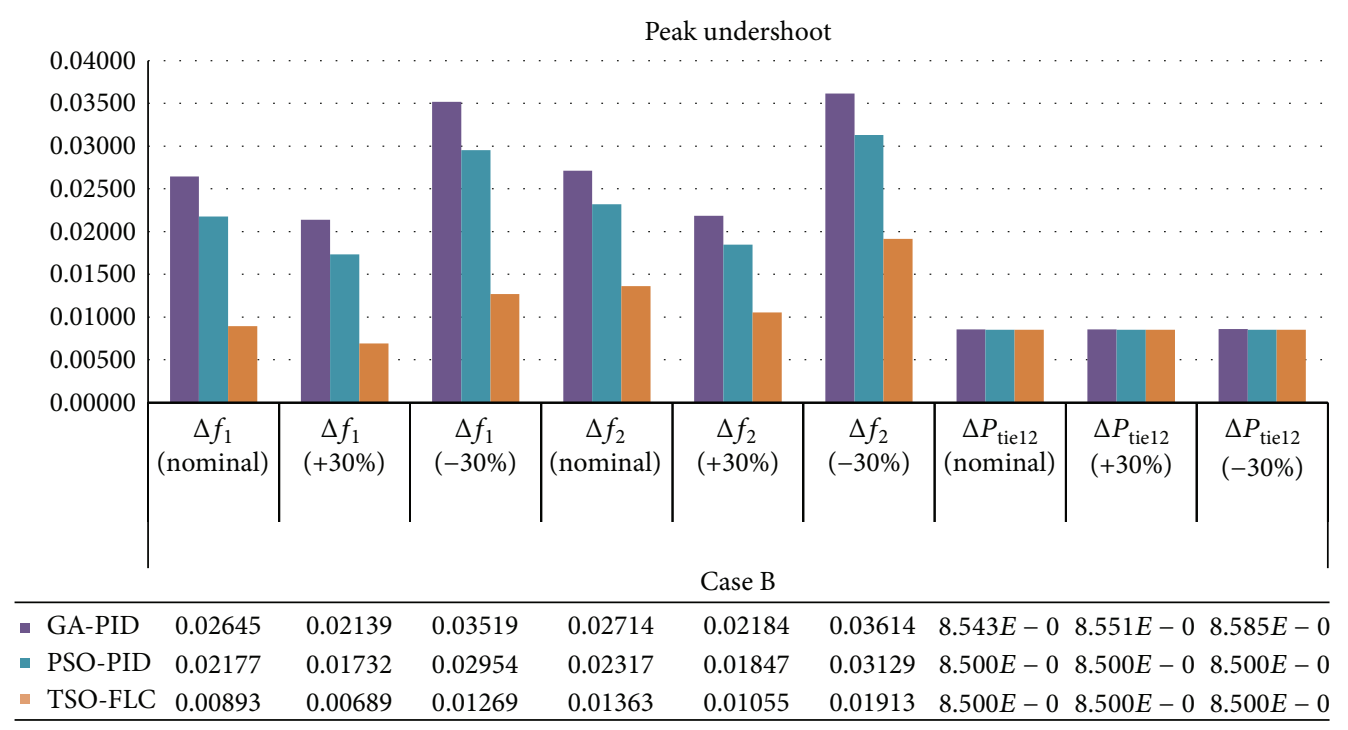

FIGURE 12: Peak undershoot comparison at $\pm 30 \%$ variation in system parameters for Case B.

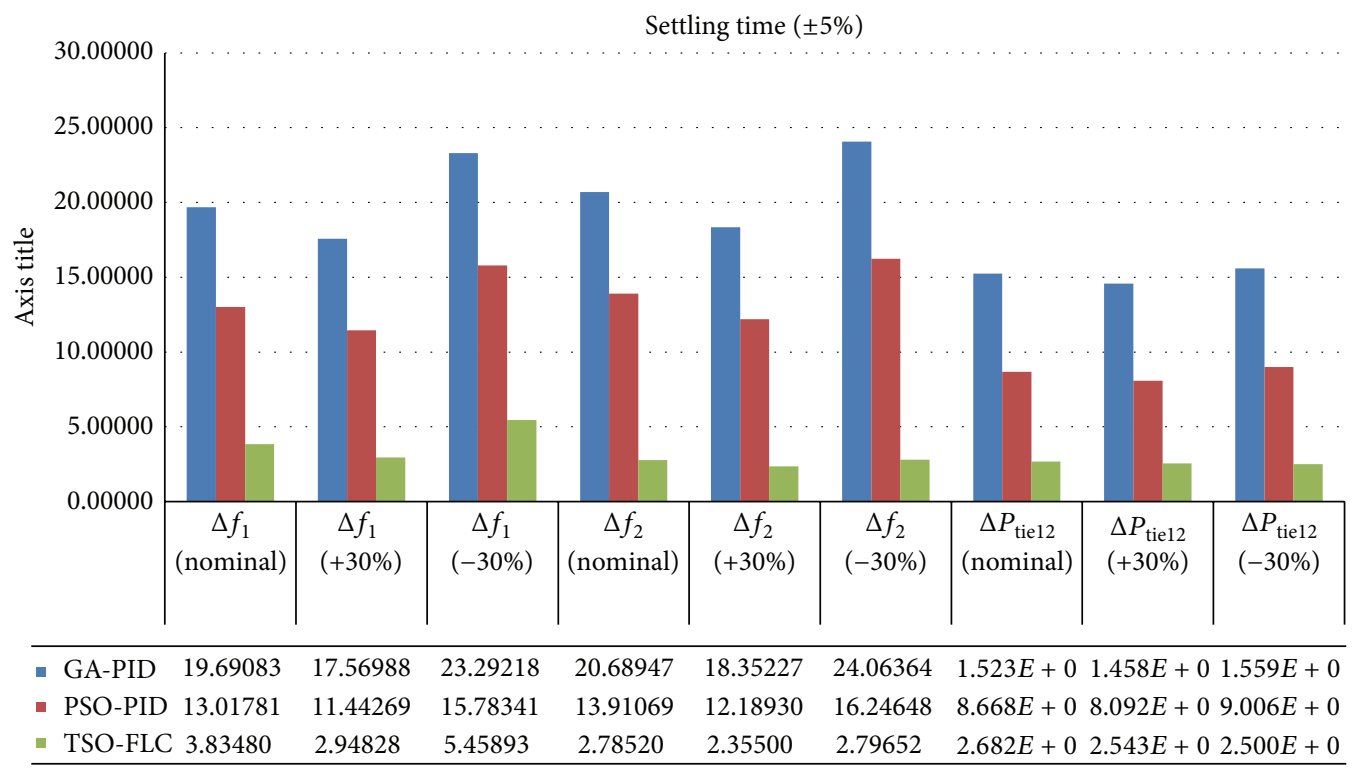

FIGURE 13: Settling time comparison at $\pm 30 \%$ variation in system parameters for Case B.

GA-PID and PSO-PID controllers. Robustness of the TSOFLC is also justified for $+30 \%$ and $-30 \%$ change in system parameters for different sets of contractual demands and again it is observed that TSO-FLC is a suitable controller for AGC in an interconnected power system.

\section{Appendix}

Speed governor: $1 /\left(1+s T_{g}\right)$

Thermal reheater: $\left(1+K_{r} s T_{r}\right) /\left(1+s T_{r}\right)$
Thermal turbine: $1 /\left(1+s T_{t}\right)$

Power system: $K_{p} /\left(1+s T_{p}\right)$.

See Tables 6 and 7.

\section{Competing Interests}

The authors declare that they have no competing interests. 


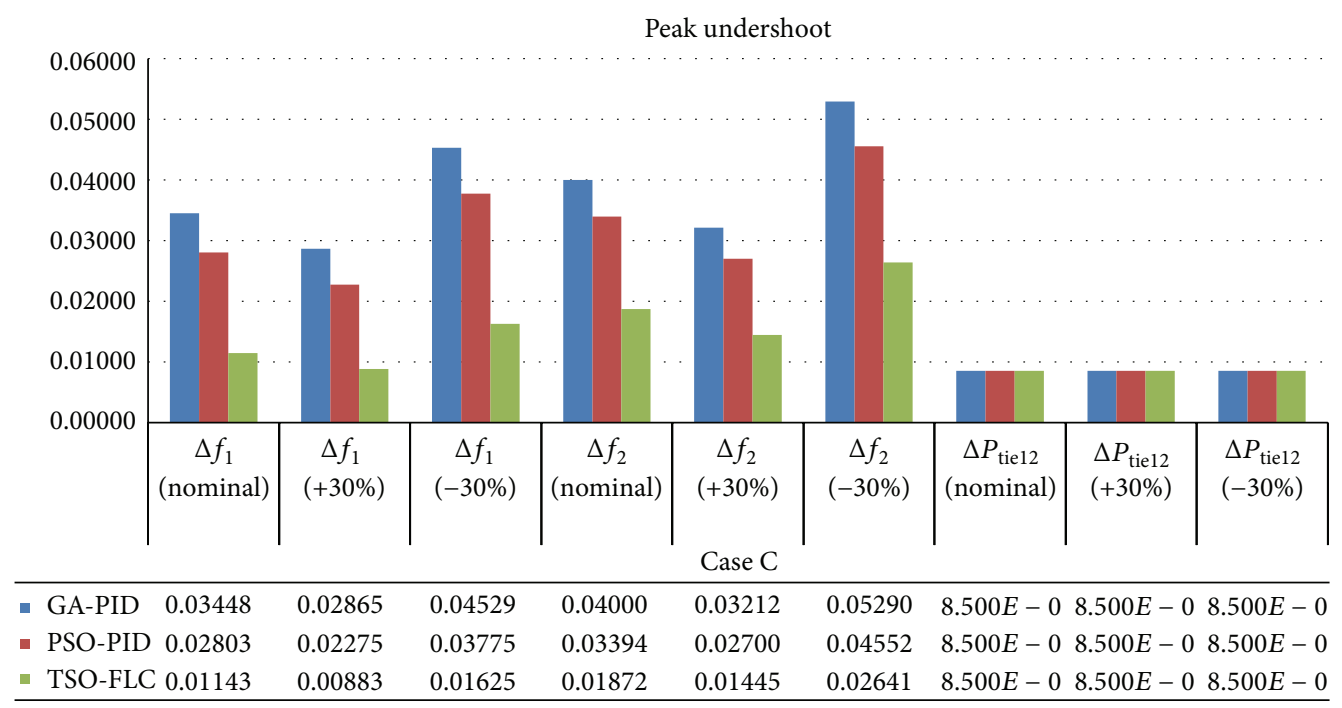

FIgure 14: Peak undershoot comparison at $\pm 30 \%$ variation in system parameters for Case C.

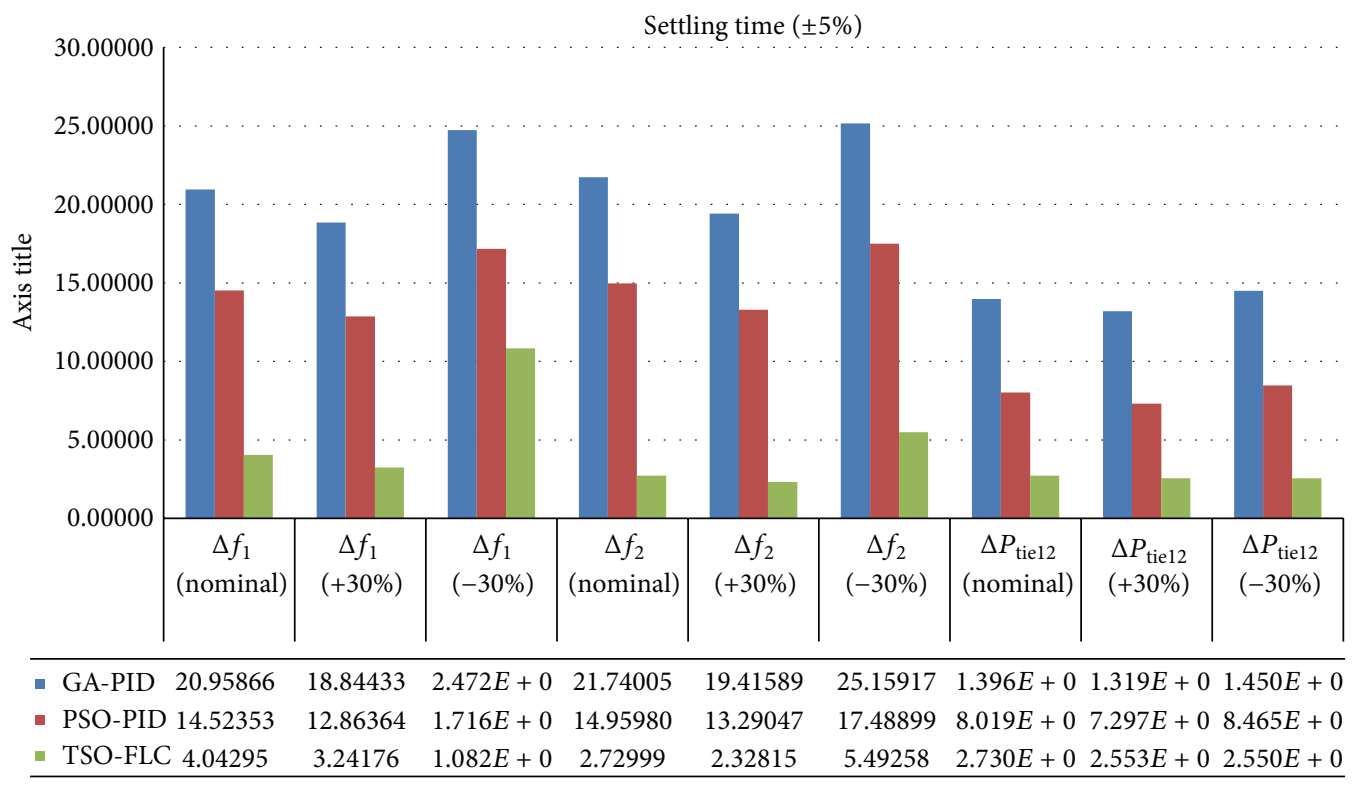

FIGURE 15: Settling time comparison at $\pm 30 \%$ variation in system parameters for Case C.

\section{References}

[1] F. Daneshfar, "Intelligent load-frequency control in a deregulated environment: continuous-valued input, extended classifier system approach," IET Generation, Transmission and Distribution, vol. 7, no. 6, pp. 551-559, 2013.

[2] I. A. Chidambaram and B. Paramasivam, "Optimized loadfrequency simulation in restructured power system with Redox flow batteries and interline power flow controller," International Journal of Electrical Power and Energy Systems, vol. 50, no. 1, pp. 9-24, 2013.

[3] A. P. Sakis Meliopoulos, G. J. Cokkinides, and A. G. Bakirtzis, "Load-frequency control service in a deregulated environment," Decision Support Systems, vol. 24, no. 3-4, pp. 243-250, 1999.
[4] F. Liu, Y. H. Song, J. Ma, S. Mei, and Q. Lu, "Optimal load-frequency control in restructured power systems," IEE Proceedings: Generation, Transmission and Distribution, vol.150, no. 1, pp. 87-95, 2003.

[5] W. C. Chan and Y. Y. Hsu, "Automatic generation control of interconnected power systems using variable-structure controllers," IEE Proceedings C: Generation Transmission and Distribution, vol. 128, no. 5, pp. 269-279, 1981.

[6] S. C. Tripathy, G. S. Hope, and O. P. Malik, "Optimisation of load-frequency control parameters for power systems with reheat steam turbines and governor deadband nonlinearity," IEE Proceedings C: Generation Transmission and Distribution, vol. 129, no. 1, pp. 10-16, 1982. 
[7] R. D. Christie and A. Bose, "Load frequency control issues in power system operations after deregulation," IEEE Transactions on Power Systems, vol. 11, no. 3, pp. 1191-1200, 1995.

[8] B. H. Bakken and O. S. Grande, "Automatic generation control in a deregulated power system," IEEE Transactions on Power Systems, vol. 13, no. 4, pp. 1401-1406, 1998.

[9] V. Donde, M. A. Pai, and I. A. Hiskens, "Simulation and optimization in an AGC system after deregulation," IEEE Transactions on Power Systems, vol. 16, no. 3, pp. 481-489, 2001.

[10] R. Roy, P. Bhatt, and S. P. Ghoshal, "Evolutionary computation based three-area automatic generation control," Expert Systems with Applications, vol. 37, no. 8, pp. 5913-5924, 2010.

[11] P. Bhatt, R. Roy, and S. P. Ghoshal, "Optimized multi area AGC simulation in restructured power systems," International Journal of Electrical Power \& Energy Systems, vol. 32, no. 4, pp. 311-322, 2010.

[12] S. P. Ghoshal, "Optimizations of PID gains by particle swarm optimizations in fuzzy based automatic generation control," Electric Power Systems Research, vol. 72, no. 3, pp. 203-212, 2004.

[13] I. Chiha, N. Liouane, and P. Borne, "Tuning PID controller using multiobjective ant colony optimization," Applied Computational Intelligence and Soft Computing, vol. 2012, Article ID 536326, 7 pages, 2012.

[14] V. Mukherjee and S. P. Ghoshal, "Intelligent particle swarm optimized fuzzy PID controller for AVR system," Electric Power Systems Research, vol. 77, no. 12, pp. 1689-1698, 2007.

[15] K. Naidu, H. Mokhlis, and A. H. A. Bakar, "Multiobjective optimization using weighted sum Artificial Bee Colony algorithm for Load Frequency Control," International Journal of Electrical Power and Energy Systems, vol. 55, pp. 657-667, 2014.

[16] D. Pelusi, "Optimization of a fuzzy logic controller using genetic algorithms," in Proceedings of the 3rd International Conference on Intelligent Human-Machine Systems and Cybernetics (IHMSC '11), pp. 143-146, Zhejiang, China, August 2011.

[17] T. Chaiyatham, I. Ngamroo, S. Pothiya, and S. Vachirasricirikul, "Design of optimal fuzzy logic-PID controller using bee colony optimization for frequency control in an isolated wind-diesel system," in Proceedings of the Transmission \& Distribution Conference \& Exposition: Asia and Pacific, vol. 1, pp. 1-4, IEEE, Seoul, The Republic of Korea, October 2009.

[18] P. Kundur, Power System Stability and Control, McGraw-Hill, New York, NY, USA, 2006.

[19] M. Parida and J. Nanda, "Automatic generation control of a hydro-thermal system in deregulated environment," in Proceedings of the 8th International Conference on Electrical Machines and Systems (ICEMS '05), pp. 942-947, Nanjing, China, September 2005.

[20] C. C. Lee, "Fuzzy logic in control systems: fuzzy logic controller. II," IEEE Transactions on Systems, Man, and Cybernetics, vol. 20, no. 2, pp. 419-435, 1990.

[21] K. R. M. Vijaya Chandrakala, S. Balamurugan, and K. Sankaranarayanan, "Variable structure fuzzy gain scheduling based load frequency controller for multi source multi area hydro thermal system," International Journal of Electrical Power and Energy Systems, vol. 53, no. 1, pp. 375-381, 2013.

[22] Y. K. Bhateshvar and H. D. Mathur, "Frequency stabilization using fuzzy logic based controller for multi-area power system in deregulated environment," in Proceedings of the 2nd International Conference on Advances in Control and Optimization of Dynamical Systems (ACODS '12), pp. 1-10, Bangalore, India, February 2012. 

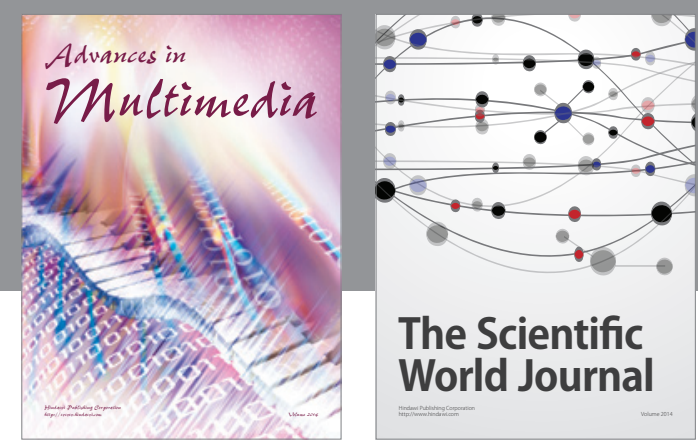

The Scientific World Journal
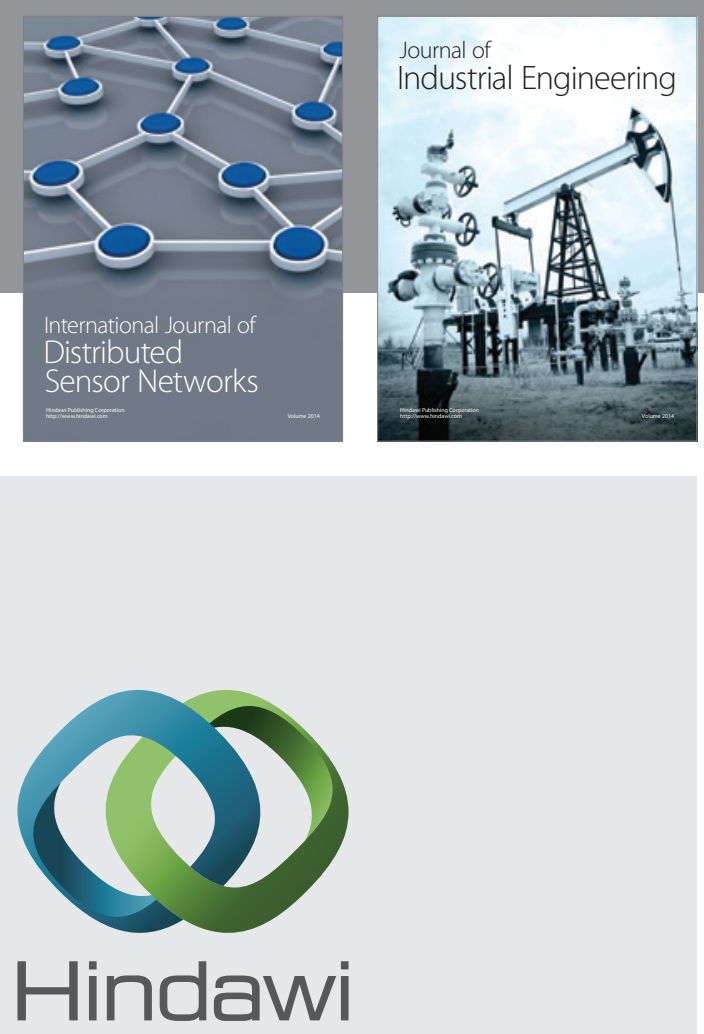

Submit your manuscripts at

http://www.hindawi.com

\section{Computer Networks} and Communications
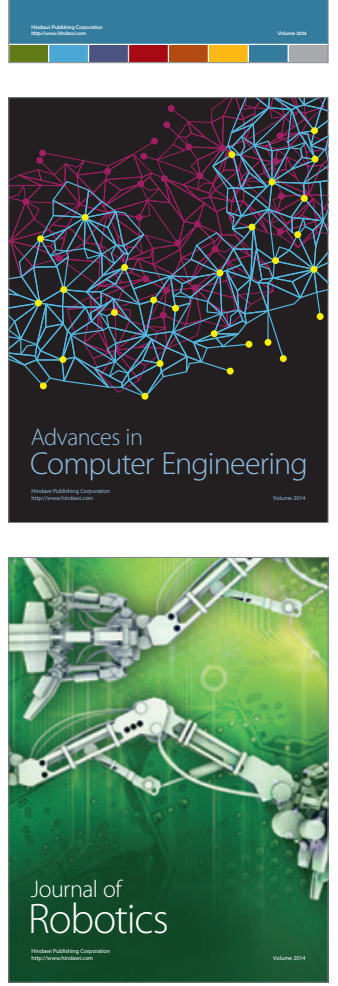
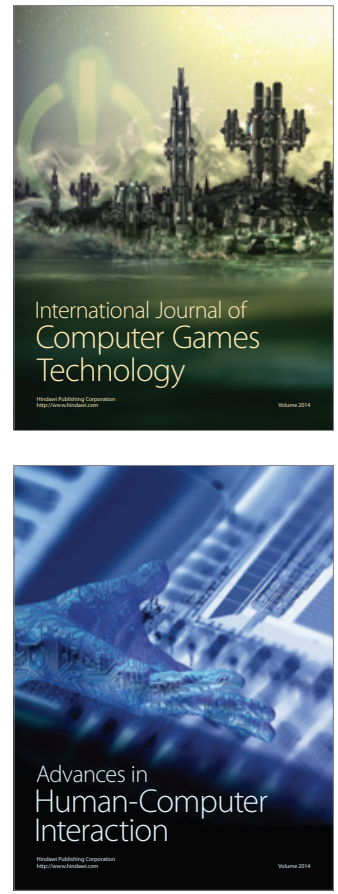
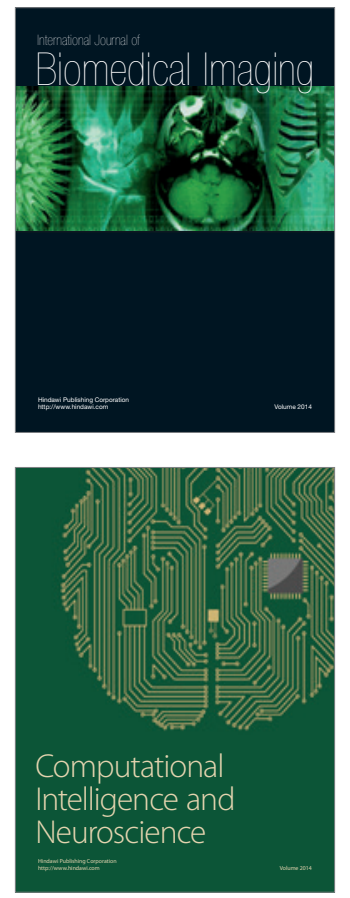
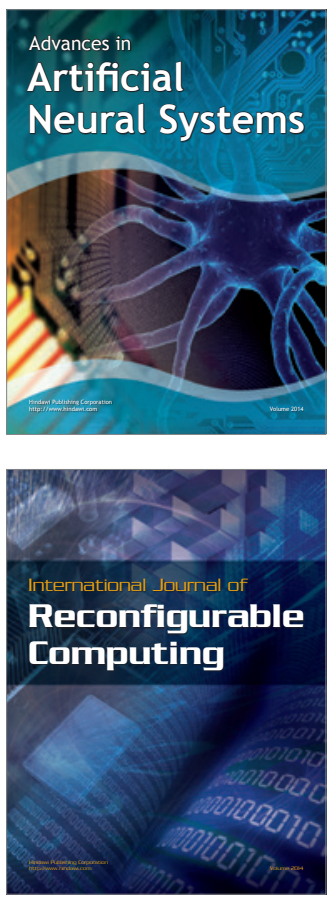
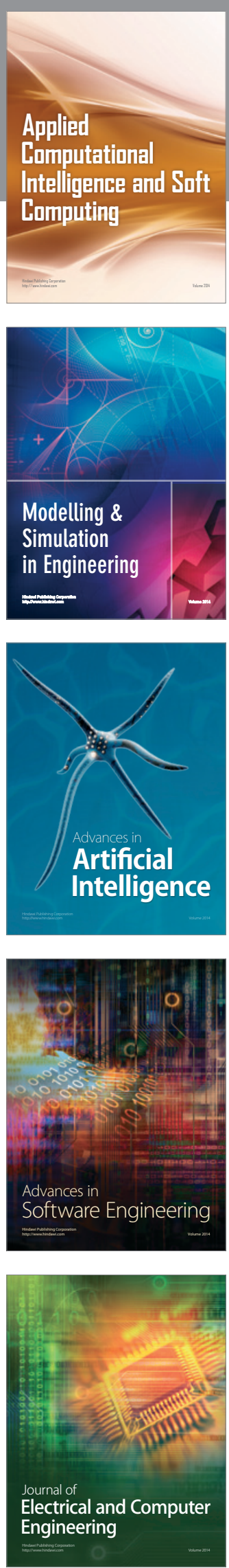